\title{
Safety Assessment of Excipients (SAFE) for Orally Inhaled Drug Products
}

\author{
Julia K. Metz1,2, Lara Scharnowske1,2, Fabian Hans', Sabrina Schnur1,2, Katharina Knoth', \\ Horst Zimmer ${ }^{3}$, Markus Limberger ${ }^{4}$, Henrik Groß1, Claus-Michael Lehr 2,5 and Marius Hittinger ${ }^{1}$ \\ ${ }^{1}$ PharmBioTec GmbH, Saarbrücken, Germany; ${ }^{2}$ Department of Pharmacy, Saarland University, Saarbrücken, Germany; ${ }^{3}$ Ursatec Verpackung GmbH, \\ Tholey, Germany; ${ }^{4}$ Quasaar GmbH, Überherrn, Germany; ${ }^{5}$ Helmholtz Institute for Pharmaceutical Research Saarland (HIPS), Saarbrücken, Germany
}

\begin{abstract}
The development of new orally inhaled drug products requires their demonstration of safety, which must be proven in animal experiments. New in vitro methods may replace, or at least reduce, these animal experiments, provided they are able to correctly predict safety or possible toxicity in humans. However, the challenge is to link in vitro data obtained in human cells to human in vivo data. We here present a new approach to the safety assessment of excipients (SAFE) for pulmonary drug delivery. The SAFE model is based on a dose response curve of 23 excipients tested on the human pulmonary epithelial cell lines A549 and Calu-3. The resulting in vitro IC50 values were correlated with the FDAapproved concentrations in pharmaceutical products for either pulmonary (if available) or parenteral administration. Setting a threshold of $0.1 \%(1 \mathrm{mg} / \mathrm{mL})$ for either value yielded four safety classes and allowed to link IC50 data as measured in human cell cultures in vitro with the concentrations of the same compounds in FDA-approved drug products. The necessary in vitro data for novel excipients can be easily generated, and the SAFE approach allows putting them into context for eventual use in human pulmonary drug products. Excipients that are most likely not safe for use in humans can be excluded early on from further pharmaceutical development. The SAFE approach thus helps to avoid unnecessary animal experiments.
\end{abstract}

\section{Introduction}

The enormous expense of and the ethical need to reduce animal experiments during preclinical trials has led to the implementation of in vitro tests in European Medicines Agency (EMA) and Organization for Economic Co-operation and Development (OECD) guidelines (EMA, 2016; OECD, 2000), and the Food and Drug Agency (FDA) Guidance for Industries "Drug Metabolism/Drug Interaction Studies in the Drug Development Process: Studies In Vitro" recommends in vitro studies of the safety and efficacy testing of potential drugs to exclude any toxic or non-effective drugs at an early stage and thus reduce the risk of failing during clinical trials (FDA, 1997). However, although regulatory agencies encourage the use of in vitro assays for the screening and evaluation of new drug formulations, animal testing is still the standard procedure to evaluate inhaled drug products (Silva and Sørli, 2018). Mice, rats, dogs and non-human primates are the most widely used animals for this purpose (Pritchard et al., 2003).
The total costs of drug development have increased from $\$ 800 \mathrm{~m}$ to $\$ 2,000 \mathrm{~m}$ per drug, whereby drug development for delivery via inhalation has reached average costs of $\$ 1,134 \mathrm{~m}$ per new drug formulation (Adams and Van Brantner, 2006). In 2004, the FDA founded the Critical Path Initiative, which is a project aimed at optimizing the costly drug development process. In the process, the determination of the safety and efficacy of new drug formulations was found to be a main cost contributor (Woodcock and Woosley, 2008). Indeed, the costs of animal testing during drug development lie between $\$ 430 \mathrm{~m}$ and $\$ 1,098 \mathrm{~m}$ per drug (DiMasi et al., 2016).

Next to the financial and ethical aspects, the questionable prediction of the human response by data from animal experiments is an ongoing discussion (Bracken, 2009; Fröhlich, 2017). Safety issues account for $24 \%$ of clinical study terminations (Harrison, 2016). According to Li (2004), some reasons for this uncertainty might be that animals have different toxic and detoxifying molecular mechanisms and thus have a different sensitivity to com-
Received October 23, 2019; Accepted January 27, 2020;

Epub January 29, 2020; @ The Authors, 2020

ALTEX 37(2), 275-286. doi:10.14573/altex.1910231

Correspondence: Marius Hittinger, PhD

PharmBioTec GmbH

Science Park 1, Campus D 1.1

66123 Saarbrücken, Germany

(m.hittinger@pharmbiotec.de)
This is an Open Access article distributed under the terms of the Creative Commons Attribution 4.0 International license (http://creativecommons.org/licenses/by/4.0/), which permits unrestricted use, distribution and reproduction in any medium, provided the original work is appropriately cited. 
pounds compared with humans. In addition, studies are limited in the investigation of toxic endpoints, the number of tested individuals is restricted, and studies struggle with dose adaptation.

An example of a successfully established in vitro assay is the skin sensitization assay based on the stimulation of different human cell lines (OECD, 2018a). However, while there has been progress in the development of some in vitro assays, there is still a lack of adequate cell- and tissue-based in vitro models for other organs such as the respiratory tract. An OECD guideline (OECD, 2018 b) now defines the certification process and the required quality controls for in vitro tests that serve the future evaluation of the assessment of human safety.

To face the challenge of developing an adequate in vitro model of the respiratory tract for safety evaluation, especially to assess nanoparticle (NP) deposition in the lung, the development of complex cell culture systems using two or more cell lines is gaining ground (Chary et al., 2018). But, no systematic data sets for the toxicological assessment of nanoparticles are available due to non-standardized parameters, different testing systems (cells, animals), and the different types and characteristics of the particles themselves (Mahmoudi et al., 2012). The many different endpoints of in vitro data obtained during safety studies - cell toxicity, proinflammatory reactions, translocation of nanoparticles in the tissue, and the resulting uptake mechanism, to name a few should be evaluated in a comprehensive way to enable their inclusion into a guideline process (Drasler et al., 2017).

The correlation of the in vitro and in vivo activity of nanoparticles (NP), such as $\mathrm{TiO}_{2}$, gold and polystyrene particles, was investigated by Rushton et al. (2010). Their in vitro assay, which was based on the secretion of reactive oxygen species (ROS), correlated significantly with in vivo observations (PMN recruitment) with an $\mathrm{R}^{2}$ of 0.81 . They proposed an NP hazard scale based on the in vivo activity of the NP surface area (Rushton et al., 2010). However, such a hazard classification related to risk (or safety) assessment of NP is still not fully established due to a lack of data on exposure processes, biokinetics, and organ-specific lung toxicity (Oberdörster, 2010; Upadhyay and Palmberg, 2018).

While the elucidation of adverse outcome pathways (AOPs) with their related cellular, tissue/organ and organism/population level key events might help to predict the toxicity of inhaled substances (Clippinger et al., 2018a; Halappanavar et al., 2019), there is still no safety classification system of substances used for oral inhalation products, including excipients, i.e. bulking agents, that are already approved by FDA for some marketed drug products. However, even larger datasets, such as those obtained by some "omics"-technologies, so far cannot overcome all limitations of in vitro and in vivo generated data. Therefore, especially the prediction of adverse effects remains a challenge (Ghallab and Bolt, 2014).

An important first step towards such an in vitro based safety classification might be the comparison of in vitro data with LD50 values, which are used as a basis for hazard classification (Strickland et al., 2018). In particular, the in vitro MTT assay has shown high sensitivity with regard to the cytotoxic effects of substances, generating a simple and reproducible determination of an IC50 value (Scherließ, 2011). Sauer et al. (2013) correlated in vivo LD50 and in vitro IC50 toxicity data from standardized MTT assays for 19 chemicals in order to categorize them into four hazard classes that predict their acute inhalative toxicity in vivo on the basis of the in vitro data. The resulting comparison allowed the identification of harmful substances. However, this classification system relates in vitro data to animal in vivo data and not to human clinical data.

In order to bridge the gap between human in vitro and human clinical data, we attempted to correlate these directly. The in vitro cytotoxicity of 23 excipients, which may be employed in an FDA-approved concentration range (i.e. considered as safe), was assessed and used to set up a four-quadrant analysis to classify the safety of other excipients to be potentially used in orally inhaled drug products.

\section{Material and methods}

\subsection{Cell lines}

The human cell line A549 (ACC107; Lieber et al., 1976) was obtained from DSMZ and was cultivated in RPMI 1640 (Roswell Park Memorial Institute 1640, gibco ${ }^{\mathrm{TM}}$, Fisher Scientific, USA) supplemented with 10\% FBS (fetal bovine serum, South American origin, PAN-Biotech, Germany) and 1\% antibiotics (penicil$\operatorname{lin}(10,000 \mathrm{U} / \mathrm{mL}) /$ streptomycin $(10,000 \mu \mathrm{g} / \mathrm{mL})$, gibco ${ }^{\mathrm{TM}}$, Fisher Scientific, USA). The human cell line Calu-3 (ATCC ${ }^{\circledR}$ HTB 55 ${ }^{\mathrm{TM}}$; Fogh et al., 1977) was cultured in MEM (minimal essential medium, gibco ${ }^{\mathrm{TM}}$, Fisher Scientific, USA) supplemented with 10\% FBS, 1\% 100x MEM NEAA (non-essential amino acids solution, gibco ${ }^{\mathrm{TM}}$, Fisher Scientific, USA), 1\% $100 \mathrm{mM}$ sodium pyruvate solution (gibco ${ }^{\mathrm{TM}}$, Fisher Scientific, USA) and 1\% antibiotics. The A549 and Calu- 3 cells were maintained in a humidified atmosphere with $5 \% \mathrm{CO}_{2}$ at $37^{\circ} \mathrm{C}$ to passage number 50 .

\subsection{Selection of the test substances}

The 23 substances listed in Table 1 together with the corresponding supplier and their solubility in water were used in the study. All substances are approved for a specified concentration range in parenteral or pulmonary drug application according to the Inactive Ingredient Search for Approved Drug Products ${ }^{1}$. A compilation of the approved concentrations from this database is given in Table 2. A pulmonary-approved concentration was available for citric acid monohydrate, citric acid anhydrous, glycerol, L-ascorbic acid, polysorbate 80 , and sodium chloride. Where no data for inhalation were given, the parenteral concentration was used.

\subsection{Determination of the in vitro IC50 value}

\section{Preparation of test concentrations}

Standardized MTT assays were performed to determine the in vitro IC50 using several dilutions of the test compounds. In the first round of assays, the concentration range was narrowed to

\footnotetext{
1 https://www.accessdata.fda.gov/scripts/cder/iig/index.cfm
} 
Tab 1: List of test substances with the related CAS number, supplier and solubility in water

\begin{tabular}{|c|c|c|c|}
\hline Substance & CAS number & Supplier & Water solubility \\
\hline Albumin from human serum & $70024-90-7$ & Baxalta, Shire, Germany & $200 \mathrm{~g} / \mathrm{L}\left(20^{\circ} \mathrm{C}\right)$ \\
\hline Benzoic acid & $65-85-0$ & Roth, Germany & $2.9 \mathrm{~g} / \mathrm{L}\left(20^{\circ} \mathrm{C}\right)$ \\
\hline Benzyl alcohol & $100-51-6$ & Fisher Scientific, United Kingdom & $40 \mathrm{~g} / \mathrm{L}\left(20^{\circ} \mathrm{C}\right)$ \\
\hline Citric acid monohydrate & $5949-29-1$ & Roth, Germany & $50 \mathrm{~g} / \mathrm{L}\left(20^{\circ} \mathrm{C}\right)$ \\
\hline Citric acid anhydrous & $77-92-9$ & PanReac AppliChem ITW Reagents, Germany & $100 \mathrm{~g} / \mathrm{L}\left(20^{\circ} \mathrm{C}\right)$ \\
\hline Docusate sodium & $577-11-7$ & Sigma Aldrich, USA & $15 \mathrm{~g} / \mathrm{L}\left(25^{\circ} \mathrm{C}\right)$ \\
\hline Glycerol & $56-81-5$ & PanReac AppliChem ITW Reagents, Germany & Fully miscible \\
\hline L(+)-Ascorbic acid & $50-81-7$ & VWR Chemicals Belgium & $50 \mathrm{~g} / \mathrm{L}\left(20^{\circ} \mathrm{C}\right)$ \\
\hline L-Alanine & $56-41-7$ & PanReac AppliChem ITW Reagents, Germany & $100 \mathrm{~g} / \mathrm{L}\left(20^{\circ} \mathrm{C}\right)$ \\
\hline L-Arginine & 74-79-3 & Sigma Aldrich, USA & $150 \mathrm{~g} / \mathrm{L}\left(20^{\circ} \mathrm{C}\right)$ \\
\hline L-Cysteine & $52-90-4$ & Roth, Germany & $25 \mathrm{~g} / \mathrm{L}\left(20^{\circ} \mathrm{C}\right)$ \\
\hline L-Methionine & $63-68-3$ & Sigma, Germany & $25 \mathrm{~g} / \mathrm{L}\left(20^{\circ} \mathrm{C}\right)$ \\
\hline L-Proline & $147-85-3$ & Roth, Germany & $1500 \mathrm{~g} / \mathrm{L}\left(20^{\circ} \mathrm{C}\right)$ \\
\hline Palmitic acid & $57-10-3$ & Merck, Germany & insoluble \\
\hline Poloxamer 188 (Kolliphor ${ }^{\circledR}$ 188) & l & Sigma Aldrich, USA & No data available \\
\hline Polyethylene glycol 200 (PEG 200) & \multirow[t]{4}{*}{$25322-68-3$} & Merck, Germany & $70 \mathrm{~g} / \mathrm{L}\left(20^{\circ} \mathrm{C}\right)$ \\
\hline Polyethylene glycol 300 (PEG 300) & & Super refined ${ }^{\mathrm{TM}}, \mathrm{CRODA}$, United Kingdom & soluble \\
\hline Polyethylene glycol 400 (PEG 400) & & Rotipuran ${ }^{\circledR}$, Roth, Germany & No data available \\
\hline Polyethylene glycol 600 (PEG 600) & & Super refined ${ }^{\mathrm{TM}}, \mathrm{CRODA}$, United Kingdom & soluble \\
\hline Polysorbate 80 (Tween-80) & \multirow[t]{2}{*}{$9005-65-6$} & Sigma Aldrich, Switzerland & Fully miscible \\
\hline Polysorbate 80 (HX2) & & NOF CORPORATE, Japan & No data available \\
\hline Polysorbate 20 (Tween 20) & $9005-64-5$ & Super refined ${ }^{\mathrm{TM}}, \mathrm{CRODA}$, United Kingdom & Fully miscible \\
\hline Sodium chloride & $7647-14-5$ & Roth, Germany & $>300 \mathrm{~g} / \mathrm{L}\left(20^{\circ} \mathrm{C}\right)$ \\
\hline
\end{tabular}

approximate the IC50. The initial concentrations were chosen based on the in vitro classification scheme (Sauer et al., 2013) of different cell culture systems, starting from 0.1 and continuing up to $10 \mathrm{mg} / \mathrm{mL}$. Dilutions were prepared in HBSS (Hank's Balanced Salt Solution, gibco ${ }^{\mathrm{TM}}$, Fisher Scientific, USA) the day before the MTT assay and stored at $4^{\circ} \mathrm{C}$. In order to specify the IC50 value in further experiments, a total of three cycles of MTT assays were performed for both cell lines. Where the IC50 of an excipient exceeded $10 \mathrm{mg} / \mathrm{mL}$, the substance was employed up to its maximal solubility in water (Tab. 1). For the relative representation of the in vitro IC50, $1 \mathrm{~g}$ (undiluted substance) was set as the $100 \%$ mark to enable unit equivalence to the FDA concentration.

\section{Cell viability measurements}

$2 \times 10^{5}$ cells/mL A549 or Calu-3 were seeded in a 96-well plate (Greiner Bio-one, Germany) in $200 \mu \mathrm{L}$ medium. $24 \mathrm{~h}$ later, the cells were visualized by light microscopy (PrimoVert, Zeiss, Ger- many) to verify epithelial confluence of nearly $100 \%$. The cells were washed twice with HBSS and $200 \mu \mathrm{L}$ of the test substances were applied. After incubation for $4 \mathrm{~h}$ on a shaker at $35 \mathrm{rpm}$ and $37^{\circ} \mathrm{C}$, the cells were washed once with HBSS. $0.5 \mathrm{mg} / \mathrm{mL}$ MTT reagent (methylthiazolyldiphenyl-tetrazolium bromide, Acros Organics, USA) was added for $4 \mathrm{~h}$ at $37^{\circ} \mathrm{C}$ and $35 \mathrm{rpm}$ and protected from light. Absorbance was measured at $550 \mathrm{~nm}$ with a plate reader (Synergy 2, BioTek Instruments $\mathrm{GmbH}$ ). To calculate the cell viability after substance exposure, a positive control of 1\% Triton X-100 (PanReac AppliChem ITW Reagents, Germany) and a negative control of HBSS were used as described in Formula 1.

Formula 1: Calculation of the cell viability based on the absorbance measurements obtained from the MTT assay

Viability $[\%]=\frac{\left(\text { absorbance }_{\text {test substance }}-\text { absorbance }_{1 \% \text { Triton } X-100)}\right)}{(\text { absorbance }} \times 100$ 
Tab. 2: List of excipients with their associated parenteral and pulmonary FDA-approved concentration from the Inactive Ingredient Search for Approved Drug Products

"No approved concentration" means that no FDA-approved product was identified.

\begin{tabular}{|c|c|c|c|}
\hline Substance & CAS number & $\begin{array}{l}\text { FDA-approved concentration } \\
\text { range - parenteral }\end{array}$ & $\begin{array}{l}\text { FDA-approved concentration } \\
\text { range - pulmonary }\end{array}$ \\
\hline Albumin from human serum & $\begin{array}{l}70024-90-7 \\
\text { FDA:9048468 }\end{array}$ & $\begin{array}{l}0.1-2 \% \\
80 \% \text { (powder for injection solution, } \\
\text { lyophilised) }\end{array}$ & no approved concentration \\
\hline Benzoic acid & $65-85-0$ & $0.0031-5 \%$ & no approved concentration \\
\hline Benzyl alcohol & $100-51-6$ & $\begin{array}{l}0.4-18 \% \\
9.45 \mathrm{mg} / \mathrm{mL} \\
\text { Powder for injection: } 10.4 \mathrm{mg} / \mathrm{mL}\end{array}$ & no approved concentration \\
\hline Citric acid monohydrate & $5949-29-1$ & $\begin{array}{l}0.05-38.46 \% \\
2.2-5.2 \mathrm{mg} / \mathrm{mL} \\
\text { Powder for injection: } 384.46 \mathrm{mg}\end{array}$ & $\begin{array}{l}0.028 \% \\
4.04 \mathrm{mg} / \mathrm{lnh} \\
4.2 \mathrm{mg} / \mathrm{mL} \\
0.002-4.04 \mathrm{mg} / \mathrm{lnh}\end{array}$ \\
\hline Citric acid anhydrous & $77-92-9$ & $\begin{array}{l}1-7 \% \\
\text { Powder for injection: } 42.19 \% \\
2-10 \mathrm{mg} / \mathrm{mL}\end{array}$ & $\begin{array}{l}0.56 \mathrm{mg} / 2 \mathrm{~mL} \\
0.0003-0.027 \%\end{array}$ \\
\hline Docusate sodium & $577-11-7$ & intramuscular: $0.015 \% \mathrm{~W} / \mathrm{V}$ & no approved concentration \\
\hline Glycerol & $56-81-5$ & $\begin{array}{l}2.5-15.36 \% \\
18.82 \mathrm{mg} / \mathrm{mL}\end{array}$ & $7.3 \%$ \\
\hline $\mathrm{L}(+)$-Ascorbic acid & $50-81-7$ & $\begin{array}{l}50.4-62.5 \% \\
\text { Powder for injection: } 0.088-48 \%\end{array}$ & $\begin{array}{l}959.5 \mathrm{mg} / \mathrm{lnh} \\
0.11-1.02 \%\end{array}$ \\
\hline L-Alanine & $56-41-7$ & no approved concentration & no approved concentration \\
\hline L-Arginine & $74-79-3$ & $\begin{array}{l}5-39 \% \\
\text { Powder for injection: } 14-78 \%, 70.7 \mathrm{~g}\end{array}$ & no approved concentration \\
\hline L-Cysteine & $52-90-4$ & $\begin{array}{l}0.01-0.1 \% \\
\text { Powder for injection: } 2.6 \%\end{array}$ & no approved concentration \\
\hline L-Methionine & $63-68-3$ & $0.004-49.2 \%$ & no approved concentration \\
\hline L-Proline & $147-85-3$ & $0.34-35.6 \%$ & no approved concentration \\
\hline Palmitic acid & $57-10-3$ & $0.001 \%$ & no approved concentration \\
\hline Poloxamer 188 (Kolliphor $\left.{ }^{\circledR} 188\right)$ & I & $0.2-0.6 \%$ & no approved concentration \\
\hline Polyethylene glycol 200 (PEG 200) & $25322-68-3$ & intramuscular: $30 \%$ & no approved concentration \\
\hline Polyethylene glycol 300 (PEG 300) & & $\begin{array}{l}4.42-65 \% \\
320 \mathrm{mg} / 5 \mathrm{~mL} \\
650 \mathrm{mg} / 1 \mathrm{~mL}\end{array}$ & no approved concentration \\
\hline Polyethylene glycol 400 (PEG 400) & & $\begin{array}{l}0.49-75.58 \% \\
0.67 \mathrm{~mL} / 1 \mathrm{~mL}\end{array}$ & no approved concentration \\
\hline Polyethylene glycol 600 (PEG 600) & & $5 \%$ & no approved concentration \\
\hline Polysorbate 80 (Tween-80) & $9005-65-6$ & $0.5-63 \%$ & $0.02 \mu \mathrm{g}$ \\
\hline Polysorbate 80 (HX2) & & $\begin{array}{l}260 \mathrm{mg} / 1 \mathrm{~mL} \\
400 \mathrm{mg} / 5 \mathrm{~mL}\end{array}$ & $\begin{array}{l}0.22 \mathrm{mg} \\
0.37 \mathrm{mg} / 2 \mathrm{~mL} \\
0.02-0.04 \%\end{array}$ \\
\hline Polysorbate 20 (Tween 20) & $9005-64-5$ & $\begin{array}{l}0.003-4.8 \% \\
\text { Powder for injection: } 0.044 \% \\
10 \mathrm{mg} / \mathrm{mL}\end{array}$ & no approved concentration \\
\hline Sodium chloride & $7647-14-5$ & $\begin{array}{l}0.9-90 \% \\
9-18 \mathrm{mg} / 1 \mathrm{~mL} \\
801.1 \mu \mathrm{l} / 1 \mathrm{~mL}\end{array}$ & $\begin{array}{l}11.25 \mathrm{mg} / 5 \mathrm{~mL} \\
8 \mathrm{mg} / 1 \mathrm{~mL} \\
8.5-27 \mathrm{mg} / 3 \mathrm{~mL} \\
0.9-1.13 \%\end{array}$ \\
\hline
\end{tabular}




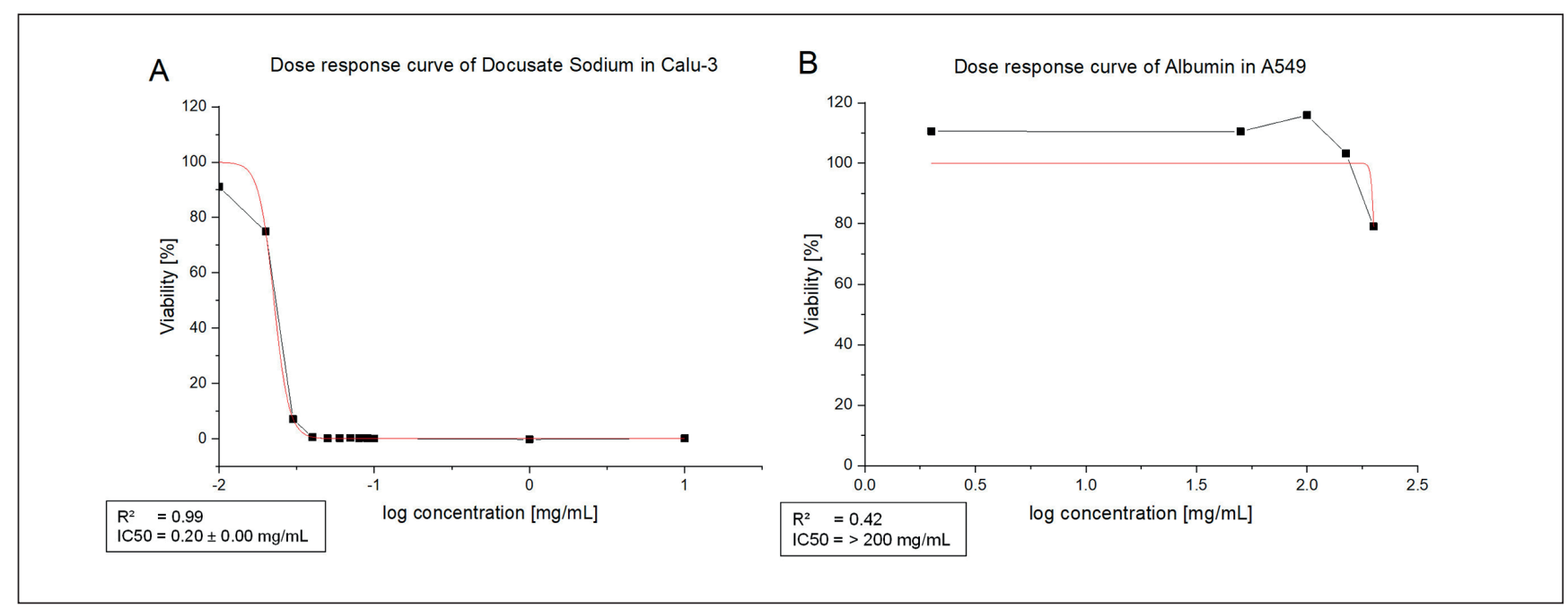

Fig. 1: Exemplary presentation of the dose response curve of docusate sodium in Calu-3 and albumin from human serum in A549 for determination of the IC50 in vitro

The applied concentration is given in $\mathrm{mg} / \mathrm{mL}$, whereby the maximal concentration is set to $1 \mathrm{~g}$ (undiluted substance). The red line indicates the sigmoidal fit used for calculation of the IC50 by OriginPro ${ }^{\circledR}$ 2019. (A) Dose response curve of docusate sodium tested on Calu-3 cells; the IC50 is $0.02 \%$. The coefficient of determination $\left(R^{2}\right)$ is 0.99 , indicating a good fit. (B) Dose response curve of albumin tested on A549 cells; the IC50 cannot be determined even up to the maximal solubility of $200 \mathrm{mg} / \mathrm{mL}$.

Generation of dose response curves and calculation of the in vitro IC50

The software OriginPro ${ }^{\circledR} 2019$ (additive, Germany) was used for IC50 calculations based on a dose response curve. The concentrations were applied in a logarithmic scale. A sigmoidal fit was performed with a top asymptote set to $100 \%$ viability and the bottom asymptote to $0 \%$ viability.

\subsection{Statistics}

For the IC50 determination performed on Calu-3 cells, 3 technical replicates (wells) in 3 independent experiments for each investigated concentration were performed. The IC50 values calculated from A549 data were based on $n=3$ wells per concentration in several experiments performed to determine the IC50 and narrow the concentrations tested next to it. Details are listed in the supplementary information in each graph. Data are summarized as the mean $\pm \mathrm{SD}$. Dose response curves and the correlation analysis were performed with the software OriginPro ${ }^{\circledR}$ 2019. A linear fit without weighting parameters was performed to calculate the Pearson r correlation coefficient.

\section{Results}

\subsection{IC50 of excipients}

The effects of the excipients on the viability of Calu-3 and A549 were determined for 23 excipients with a standardized MTT assay. The IC50 is given in \% and scaled logarithmically. Two examples of dose response curves and the calculation of the test- ed excipient are shown for docusate sodium (CAS: 577-11-7) on Calu-3 cells (Fig. 1A) and albumin from human serum for A549 (Fig. 1B). Docusate sodium has an IC50 of $0.02 \%$ tested on Calu-3 cells. For albumin, no determination of the IC50 value on A549 was possible (IC50 > $200 \mathrm{mg} / \mathrm{mL}$ ). The dose response curves with the IC50 calculation for all tested excipients are shown in Figures $\mathrm{S} 1$ and $\mathrm{S}^{2}$.

The in vitro IC50 values are listed in Table 3. For the substances albumin from human serum, L-alanine, L-cysteine, L-methionine, palmitic acid, poloxamer 188, and the polyethylene glycols (PEG) 200-600, no calculation of the IC50 was possible in their aqueous solubility range.

No converging fit was obtained in the testing of glycerol (Calu-3), L-proline (A549), and sodium chloride (A549 and Calu-3), but an approximation of the IC50 by the software was possible. In vitro calculation of the IC50 was successful for the remaining 11 excipients. The results were compared to the classification by Sauer et al. (2013) (Tab. 3). A comparison of A549 and Calu-3 showed that the observed IC50 values were in a similar range but did not correlate in a regression analysis (Fig. S3 ${ }^{1}$; Tab. S2 ${ }^{1}$ ).

\subsection{Linear correlation of FDA-approved concentration range and in vitro IC50}

For evaluation of the linear correlation between the in vitro IC50 value and the approved FDA concentration, regression analysis was performed.

Calu-3 IC50 values (Tab. 3) of the substances benzyl alcohol, citric acid monohydrate, citric acid anhydrous, docusate sodium, glycerol, L-ascorbic acid, L-arginine, L-cysteine, L-proline,

2 doi:10.14573/altex.1910231s 
Tab. 3: List of excipients with the IC50 [\%] in A549 and Calu-3 cells in comparison to the classification by Sauer et al. (2013)

\begin{tabular}{|c|c|c|c|c|}
\hline Substance & CAS number & $\begin{array}{l}\text { A549 } \\
\text { IC50 in vitro [\%] }\end{array}$ & $\begin{array}{l}\text { Calu-3 } \\
\text { IC50 in vitro [\%] }\end{array}$ & $\begin{array}{l}\text { Classification } \\
\text { according to } \\
\text { Sauer et al. (2013) }\end{array}$ \\
\hline Albumin from human serum & l & > 20 (solubility reached) & $>20$ (solubility reached) & Class 4 \\
\hline Benzoic acid & $65-85-0$ & $0.048 \pm 0.100$ & not measured & Class 2 \\
\hline Benzyl alcohol & $100-51-6$ & $0.344 \pm 0.013$ & $0.305 \pm 0.032$ & Class 3 \\
\hline Citric acid monohydrate & $5949-29-1$ & $0.095 \pm 0.003$ & $0.038 \pm 0.001$ & Class 2 \\
\hline Citric acid anhydrous & $77-92-9$ & $0.018 \pm 0.003$ & $0.032 \pm 0.001$ & Class 2 \\
\hline Docusate sodium & $577-11-7$ & $0.020 \pm 0.001$ & $0.002 \pm 0.000$ & Class 1-2 \\
\hline Glycerol & $56-81-5$ & $38.875 \pm 0.054$ & $\begin{array}{l}\text { Fit does not converge } \\
\text { (range 1-25) }\end{array}$ & Class 4 \\
\hline $\mathrm{L}(+)$-Ascorbic acid & $50-81-7$ & $0.092 \pm 0.002$ & $0.017 \pm 0.003$ & Class 2 \\
\hline L-Alanine & $56-41-7$ & $>10$ & $>10$ & Class 4 \\
\hline L-Arginine & $74-79-3$ & $2.162 \pm 0.220$ & $0.946 \pm 0.070$ & Class 4 \\
\hline L-Cysteine & $52-90-4$ & $>2.5$ & $1.214 \pm 0.087$ & Class 4 \\
\hline L-Methionine & $63-68-3$ & $>2.5$ & $>2.5$ & Class 4 \\
\hline L-Proline & $147-85-3$ & $\begin{array}{l}\text { Fit does not converge } \\
\text { (range 19-25) }\end{array}$ & $11.651 \pm 0.629$ & Class 4 \\
\hline Poloxamer 188 (Kolliphor ${ }^{\circledR} 188$ ) & l & solubility reached & solubility reached & Class 4 \\
\hline Polyethylene glycol 200 (PEG 200) & \multirow[t]{4}{*}{$25322-68-3$} & \multirow[t]{4}{*}{$>10$} & \multirow[t]{4}{*}{$>10$} & Class 4 \\
\hline Polyethylene glycol 300 (PEG 300) & & & & Class 4 \\
\hline Polyethylene glycol 400 (PEG 400) & & & & Class 4 \\
\hline Polyethylene glycol 600 (PEG 600) & & & & Class 4 \\
\hline Polysorbate 80 (Tween-80) & \multirow[t]{2}{*}{$9005-65-6$} & $0.147 \pm 0.017$ & $1.117 \pm 0.071$ & Class 3 \\
\hline Polysorbate 80 (HX2) & & $0.118 \pm 0.007$ & $0.224 \pm 0.030$ & Class 3-4 \\
\hline Polysorbate 20 (Tween 20) & $9005-64-5$ & $0.024 \pm 0.009$ & $0.120 \pm 0.011$ & Class 2-3 \\
\hline Sodium chloride & $7647-14-5$ & $\begin{array}{l}\text { Fit does not converge } \\
\text { (range 1-10) }\end{array}$ & $\begin{array}{l}\text { Fit does not converge } \\
\text { (range 1-10) }\end{array}$ & Class 4 \\
\hline
\end{tabular}

polysorbate 80 , polysorbate $80 \mathrm{HX} 2$, polysorbate 20 , and sodium chloride were plotted against the approved FDA concentration (Tab. 2). The percentage ranges of the FDA concentrations given for the pulmonary and parenteral application were included. Figure 2 shows a positive slope of the regression line of $0.42 \pm 0.12$ and a coefficient of determination $\left(\mathrm{COD}, \mathrm{R}^{2}\right)$ of 0.31 , indicating a poor correlation.

Next, a regression analysis was performed for the A549 cell line (Fig. 3). The IC50 values (Tab. 3) and the FDA-approved concentrations (Tab. 2) for benzoic acid, benzyl alcohol, citric acid monohydrate, citric acid anhydrous, docusate sodium, glycerol, L-ascorbic acid, L-arginine, L-proline, polysorbate 80, polysorbate $80 \mathrm{HX} 2$, polysorbate 20 , and sodium chloride were plotted. A positive slope of the regression line of $0.60 \pm 0.12$ was obtained by performing a correlation analysis with an $\mathrm{R}^{2}$ of 0.49 . In comparison to the correlation using the Calu- 3 cell line, the $\mathrm{R}^{2}$ indicates in the A549 plot a slightly better correlation.

\subsection{The safety assessment for excipients (SAFE)}

\subsubsection{Safety assessment based on the IC50 in vitro and the FDA-approved concentration}

The drawback of the linear regression analysis using the FDA data is that there might be some buffer for a higher approved concentration as the approved value cannot be compared with an LD50 derived from animals. However, knowledge from the Sauer et al. (2013) publication can be utilized to consider known hazard effects. Using the classification suggested in that paper on the IC50 values of the tested excipients against the FDA-approved concentration range, a four-class division was obtained.

The concentration of $0.1 \%(1 \mathrm{mg} / \mathrm{mL})$ was determined as a critical concentration for the IC50 due to the first occurrence of toxicological effects in the cellular test system according to the acute toxicity classification of the UN (class \#1-2: fatal if inhaled, class \#3: toxic if inhaled, class \#4-5: harmful and maybe 


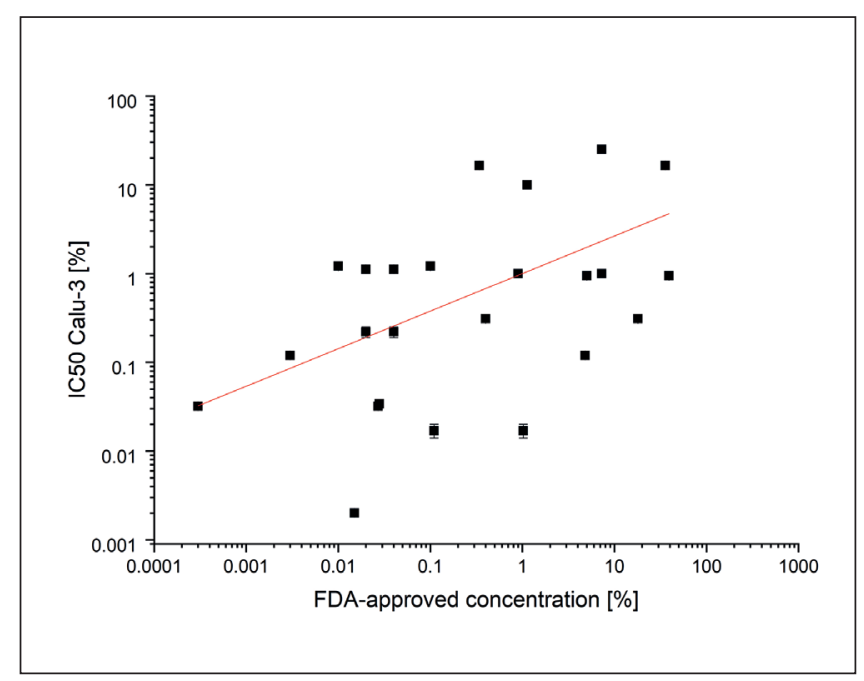

Fig. 2: Regression analysis of IC50 [\%] in vitro in Calu-3 cells vs FDA approved concentration range [\%]

The concentration of the calculated in vitro IC50 values was based on a maximal concentration of $1 \mathrm{~g}$. The approved concentrations were obtained from the FDA's database on inactive ingredients. The values for the linear regression analysis are: slope: $0.42 \pm 0.13$, sum square of errors: 20.90 ; Pearson R: 0.55 ; coefficient of determination (COD, $\mathrm{R}^{2}$ ): 0.31 ; Correlation $\mathrm{R}^{2}$ : 0.28 .

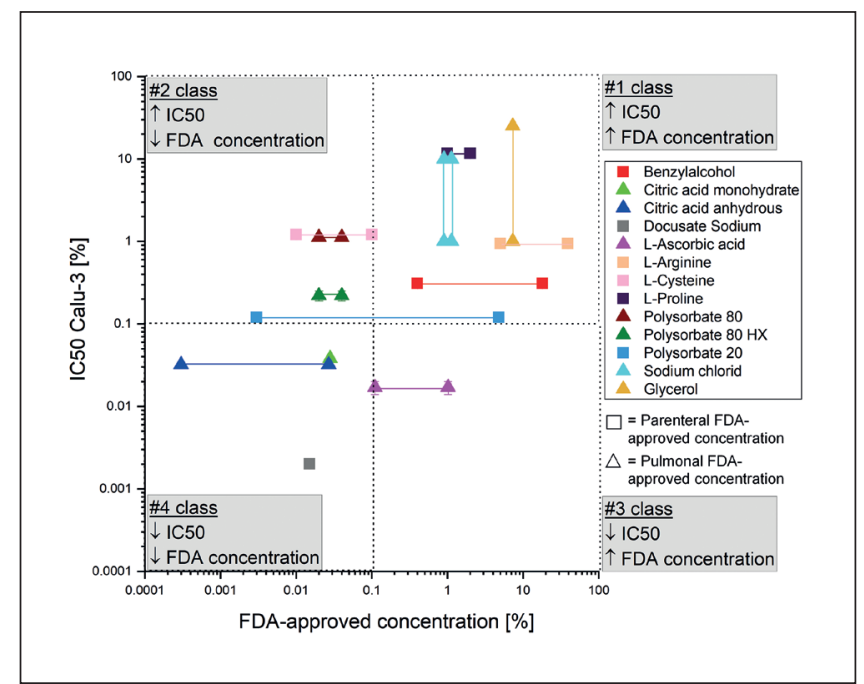

Fig. 4: The IC50 values of the excipients tested in the Calu-3 cell line and the FDA-approved concentration ranges can be set up in a four-class system

The diagram consists of the calculated IC50 values plotted against the approved FDA concentrations (squares: parenteral approved concentration, triangles: pulmonary approved concentration) for the tested excipients. Dividing this diagram into four regular squares from $0.1 \%$ IC50 to $0.1 \%$ FDA and up to $100 \%$ IC50/FDA, results in a four-class system. \#1 class: high IC50, high FDA-approved concentration, \#2 high IC50, low FDA-approved concentration, \#3 class: low IC50, high FDA-approved concentration, \#4 class: low IC50, low FDA-approved concentration.

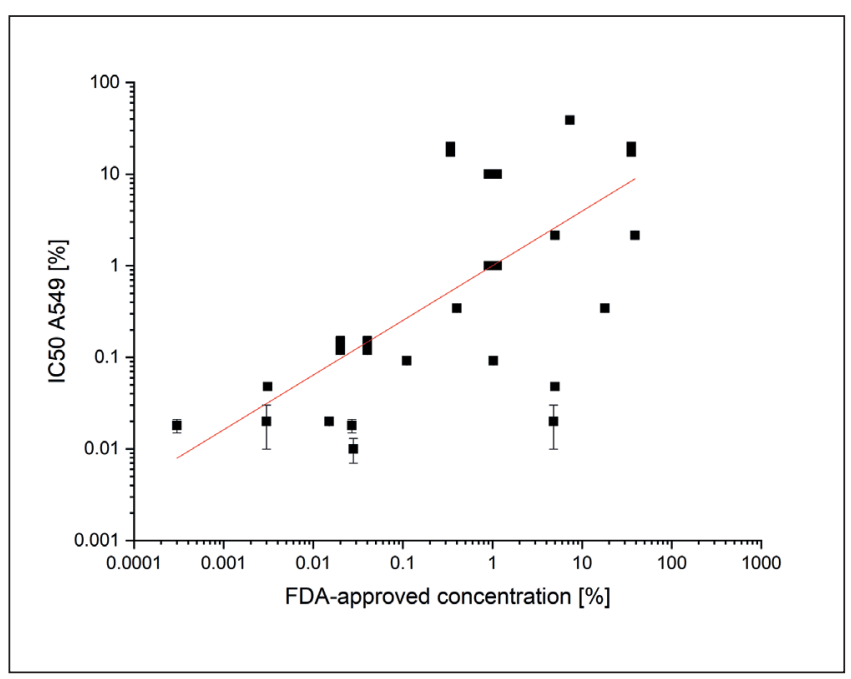

Fig. 3: Regression analysis of IC50 [\%] in vitro in A549 cells vs approved FDA concentration range [\%]

The concentration of the calculated in vitro IC50 values was based on a maximal concentration of $1 \mathrm{~g}$. The approved concentrations were obtained from the FDA's database on inactive ingredients. The values of the linear regression analysis are: slope: $0.60 \pm 0.12$, sum square of errors: 18.24 ; Pearson R: 0.70 ; coefficient of determination (COD, $\mathrm{R}^{2}$ ): 0.49 ; Correlation $\mathrm{R}^{2}$ : 0.47 .

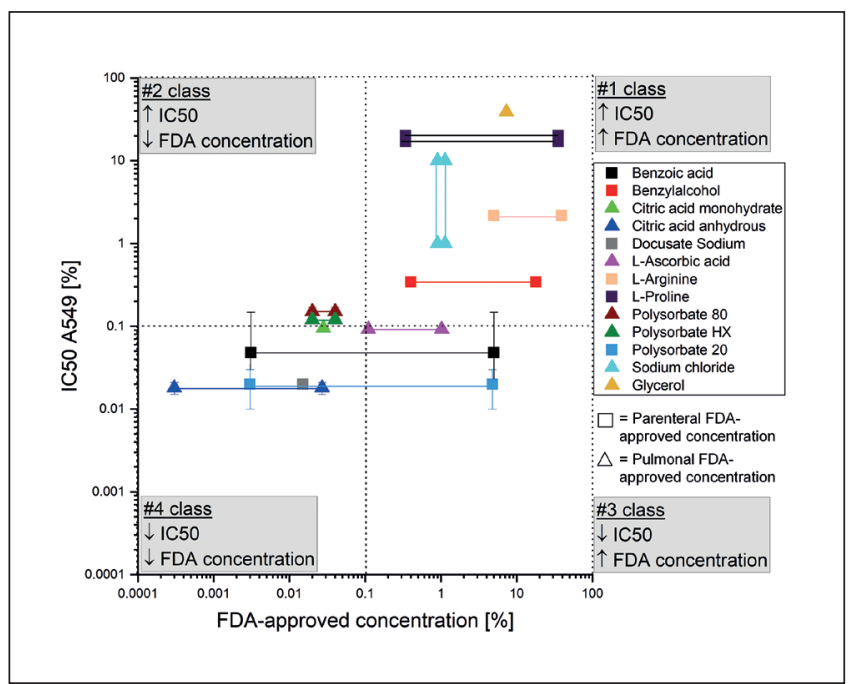

Fig. 5: The IC50 values of the excipients tested in the A549 cell line and the FDA-approved concentration ranges can be set up in a four-class system

The diagram consists of the calculated IC50 values plotted against the approved FDA concentrations (squares: parenteral approved concentration, triangles: pulmonary approved concentration) for the tested excipients. Dividing this diagram into four regular squares from $0.1 \%$ IC50 to $0.1 \%$ FDA and up to $100 \%$ IC50/FDA, results in a four-class system. \#1 class: high IC50, high FDA-approved concentration, \#2 high IC50, low FDA-approved concentration, \#3 class: low IC50, high FDA-approved concentration, \#4 class: low IC50, low FDA-approved concentration. 
Tab. 4: Line-up of the four class-based classification by Sauer et al. (2013) and the tested concentrations ranges for the SAFE-approach in \%

\begin{tabular}{|l|l|l|}
\hline In vitro hazard class & $\begin{array}{l}\text { Concentration range for cell monolayer [mg/mL] } \\
\text { (Sauer et al., 2013) }\end{array}$ & Concentration range for SAFE-classification [\%] \\
\hline$\# 1$ & $<0.1$ & $<0.01$ \\
\hline$\# 2$ & $0.1-1$ & $0.01-0.1$ \\
\hline$\# 3$ & $1-10$ & $0.1-1$ \\
\hline$\# 4$ & $>10$ & 1 \\
\hline
\end{tabular}

harmful if inhaled (United Nations, 2017)). The excipients with an IC50 below $0.1 \%$ were categorized in classes 1 and 2 according to Sauer et al. (2013) (Tab. 4). Above an IC50 of $0.1 \%$, no safety concerns are obvious, so that a resulting classification into class 4 is likely. The corresponding classification of all tested excipients according to the system proposed by Sauer et al. (2013) is shown in Table 3.

A four-class system is obtained by setting $0.1 \%$ as the limit line of cellular toxicity effects and outlining evenly distributed squares in the fit of IC50 and the approved FDA concentration. In class 1, the in vitro IC50 and the FDA-approved concentration are consistently high. For the Calu-3 cell line, benzyl alcohol, glycerol, L-proline, sodium chloride, L-arginine and, in the border region, polysorbate- 20 , were categorized as class 1 . These excipients are non-toxic according to the system of Sauer et al. (2013). In the A549 cell line, class 1 substances have similar values, except polysorbate 20, which is categorized as class 3-4. Class 2 is the quadrant to the left, which is characterized by a high IC50 value and a lower FDA-approved concentration. Polysorbate 80, polysorbate $80 \mathrm{HX}$, polysorbate 20, and L-cysteine tested on Calu-3 cells, and polysorbate 80 and polysorbate $80 \mathrm{HX} 2$ tested on A549 cells fall into class 2. Class 3 is characterized by a high FDA-approved concentration and a low IC50 value. L-ascorbic acid tested on Calu-3 belongs to this class, whereas in A549 L-ascorbic acid, benzoic acid and polysorbate 20 are classified here. Class 4 contains the squares at the intersection with a low IC50 value and a corresponding low FDA concentration. Citric acid, docusate sodium, and benzoic acid fall into this category for Calu-3, with an additional test of benzoic acid and citric acid on the limital zone to class 3 on A549. This classification system is visualized for $\mathrm{Ca}-$ lu-3 in Figure 4 and for A549 in Figure 5.

\subsubsection{Consequences of the four classes for safety assessment of excipients (SAFE)}

The $S A F E$ classification can help to estimate, based on in vitro IC50 data, whether pulmonary administration to humans will be safe or not. This estimation is based on the results presented in Figures 4 and 5 . The concentration of $0.1 \%$ (which indicates problems with the animal toxicity study in the preclinical phase) forms the center of the coordinate system and is the dividing line for the resulting classification (Fig. 6).

A higher IC50, which is above $0.1 \%$ (classes 1 and 2), is worth considering for further development. A lower IC50 below $0.1 \%$,

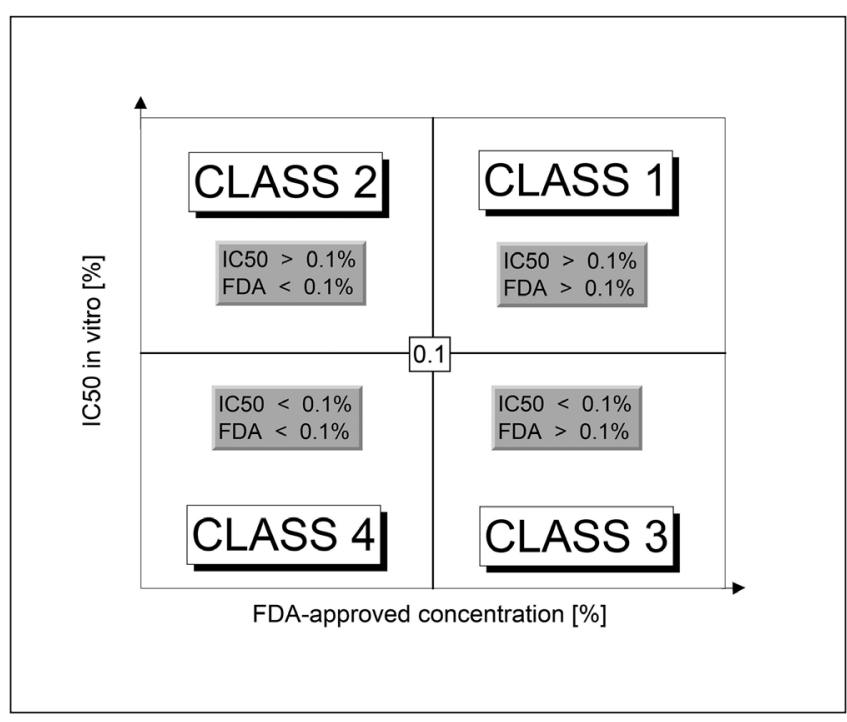

Fig. 6: The SAFE classification

Divided into 4 classes, SAFE gives an indication of the categorization of the in vitro IC50 value to the FDA-approved concentration. Arrangement of the 4 classes: Class 1: IC50 is higher than $0.1 \%$, the correlated FDA concentration is higher than $0.1 \%$; Class 2: IC50 is higher than $0.1 \%$, the correlated FDA concentration is lower than $0.1 \%$; Class 3 : IC50 is lower than $0.1 \%$, the correlated FDA concentration is higher than $0.1 \%$; Class 4: IC50 is lower than $0.1 \%$, the correlated FDA concentration is lower than $0.1 \%$.

which is here referred to as classes 3 and 4, is not recommended for further development. The target class 1 implements a high IC50 and a high FDA-approved concentration, making it the most appropriate class to continue with further testing and potential use in humans. Most tested excipients are classified in this non-toxic category and no safety issues are expected during subsequent pre-clinical and clinical development. In class 2 , the tested in vitro concentration could be increased in view of a higher FDA-approved concentration. In classes 3 and 4, in correspondence with the classification by Sauer et al. (2013), cytotoxicity is obvious, and therefore considering such compounds for further development steps may be risky. For a class 4 substance, the approval requirements are likely to be complicated. 
The SAFE system helps to estimate the risk of excipients and the chance of obtaining FDA approval by using them in new drug formulations.

\section{Discussion}

The concept of an in vitro-in vivo-correlation (IVIVC) aims to predict the bioavailability and the efficacy of the tested drug product based on its release kinetics (Barakat et al., 2015; Shen and Burgess, 2016) in relation to the Biopharmaceutical Classification System (BCS) adapted by the FDA (CDER/FDA, 2017). In line with this classic BCS, a pulmonary biopharmaceutical classification (pBCS) was described, implementing the impacts of lung biology in terms of lung metabolism, drug-drug interactions, presence of transporters and mucus, protein binding, clearance, surfactant, and formulation properties like size, solubility, and used excipients (Hastedt et al., 2016; Gonda, 2006). Despite the consideration of all these physiological aspects, no linear IVIVC can predict the in vivo response in the lung on the basis of an in vitro dose dependency (Eixarch et al., 2010). Therefore, an in vitro testing strategy for predicting the respiratory toxicity of chemicals and drug products is still needed. One initial step toward this goal is the development of a classification system to predict the safety of chemicals and drug products.

The present work is an attempt to break down the complexity of the physiological aspects of the lung to gradually approach an in vitro test strategy for orally inhaled drug products that can support formulation development by addressing cytotoxicity towards pulmonary epithelial cells. Sauer et al. (2013) already established an in vitro hazard classification system by correlating IC50 values of 19 substances tested in 3 cellular systems for different incubation periods (A549 - 24 hours; EpiAirway ${ }^{\mathrm{TM}}$ - 3 hours; MucilAir ${ }^{\text {TM }}$ system - 24 hours) with the GHS classification. We slightly modified the experimental setup of Sauer et al. (2013) by shortening the incubation period to $4 \mathrm{~h}$, in order to consider the exposure period mentioned in the OECD acute inhalation toxicity guideline 436 (OECD, 2009), and by using A549 and Calu-3 cells. Challenge of the cells with the test compounds in a salt buffer for 4 instead of $24 \mathrm{~h}$ was intended to reduce the influence of both cell proliferation and the incubation medium on the results.

The resulting in vitro hazard classification includes different concentration ranges for the cellular systems to predict GHS respiratory category. Independent of the chosen cell system and incubation period, a concentration of $0.1 \%$ was in all cases associated with GHS category $\leq 3$. The classification according to Sauer et al. (2013) formed the basis for the in vitro IC50 limiting value of $0.1 \%$ of the $S A F E$ classification. In summary, there is no guarantee to have a safe compound when the IC50 is above the threshold of $0.1 \%$, but it is a clear indication. We recommend when developing a new drug product also to test prolonged incubation periods and other cell types as applicable.

To obtain an IVIVC based on the in vitro IC50 evaluation, we attempted to correlate the in vitro data on the excipients with the in vivo LD50 based GHS classification. A direct comparison with the GHS classification based on oral LD50 data is not possible for pharmaceutical excipients as most of them are classified as safe (GHS class 4/5, see Tab. S1 ${ }^{1}$ ). However, upon compilation of the GHS classification for acute pulmonary toxicity of the tested excipients (Tab. $\mathrm{S}^{1}{ }^{1}$ ), we found a large data gap for pulmonary LD50 values, so that no effective, direct correlation of the IC50 values with the in vivo data on pulmonary toxicity was possible (ECHA, search for chemicals, guidance on the safe use of the substance; Rowe et al., 2009; GESTIS Stoffdatenbank; search in NICEATM Integrated Chemical Environment data base (ICE)).

For pulmonary classification, the exposure route is divided into gases, vapors, dusts and mists (United Nations, 2017). No increased GHS classes were obtained for these application forms. Gases of benzyl alcohol were assigned GHS Class 1, while docusate sodium, sodium chloride, and polysorbate 20 were assigned to GHS Class 2. This use of different routes of administration in vivo makes it difficult to achieve a standardized in vitro comparison.

More complex cell culture systems have been developed with the aim of achieving a better IVIVC (Fizeșan et al., 2018). By testing the cytotoxicity of inhaled drug products in a commercially available human 3D cellular model of the lung (MucilAir), Sivars et al. (2018) found a good correlation of in vitro respiratory toxicity data based on measurement of cell barrier integrity, cell viability, ciliary beating frequency $(\mathrm{CBF})$, mucociliary clearance, and the resulting cytokine release, with in vivo toxicity data.

In the mentioned study, MucilAir was cultivated under serum-free conditions to avoid the use of FCS, which is associated with pain and suffering of the animals from which it is obtained. The amount and type of serum proteins is of particular importance as they can influence the binding and activity of compounds and nanomaterials (Drasler et al., 2017; Moore et al., 2015). Therefore, we challenged the cells in salt buffer without FCS, but also intend to replace FCS in the culture medium by defined supplements in future studies.

In addition to the more complex 3D cell culture systems like MucilAir, attempts have been made in recent years to recreate the physiology of the lung using microfluidic systems. Huh et al. (2011) were able to reconstitute the toxic and inflammatory responses of the lung in comparison to exposure data of silica particles from mice by using a "lung-on-a-chip" device. However, more complex systems such as co-cultures or chip-based systems are challenging to validate (Huh et al., 2011; Dipasri et al., 2016).

The in vitro test strategy we followed in this study might be extended and combined with further specific methods (e.g., surfactometry) and summarized into a safety assessment of the test compound. Such integrated test strategies for the in vitro prediction of acute inhalation toxicity were discussed in 2018 at the workshop "Alternative approaches for acute inhalation toxicity testing to address global regulatory and non-regulatory data requirements" (Clippinger et al., 2018b). The paper summarizes the current state of inhalative in vitro technologies as well as the criteria that must still be met to overcome the obstacles for guideline acceptance, such as an information transfer from animal experiments, the correct application of dosimetry and realization to industrial applications with their resulting technical needs. 
The toxic effects of substances in the lung depend on different parameters, such as airborne concentration, particle size, solubility in surfactant, reactivity, air exchange, rate of exposure, interactions with other inhaled substances, and the specific immunological response (Bakand et al., 2005). In particular, the consideration of the immunological reaction of the test system is a major part of the safety assessment of a compound. By setting up a tetraculture of A549, HMC-1, THP-1, and EA.hy 926 and using the Vitrocell ${ }^{\circledR}$ CLOUD system, Klein et al. (2013) could show that inflammatory responses are overpredicted under submerged conditions. This could be an explanation for cases where the FDA-approved concentration was high but the IC50 value was low ( $S A F E$ class 3). To avoid this overestimation, air-liquid interface (ALI) exposure systems - potentially covered with mucus or surfactant - and the dosimetry should be taken into account (Paur et al., 2011).

In order to investigate nanomaterials, existing in vitro assays such as the NR8383 alveolar macrophage assay described by Wiemann et al. (2018) can be combined with $S A F E$, taking ongoing discussions on dosimetry (Wiemann et al., 2018; Schmid and Cassee, 2017) and experimental setups (Kong et al., 2011) into account. Dosimetry is an important aspect of focusing the deposition of particles or substances in the alveolar region. Donaldson et al. (2008) obtained a high IVIVC by expressing the dose in terms of A549 cell culture surface area. Schmid and Stoeger (2016) set up a dose-response curve by plotting the particle surface area against the acute inflammatory reaction (PMN influx), attaining a high $\mathrm{R}^{2}$ of 0.77 .

Next to the inflammatory reaction, the influence of compounds on lung surfactant is important as some substances can cause alveolar collapse after inhalation (King, 1982; Schleh et al., 2013). To investigate the influence of airborne substances on lung surfactant, Sørli et al. (2016) established the constrained drop surfactometer (CDS). Their results indicate that the size and the effect of the applied substance on the surface tension of the lung surfactant has an impact on the toxic effect, and can be employed to predict alveolar collapse.

These results from surfactometry as well as the investigation of the inflammatory response induced by substances in the lung indicate that safety investigations of orally inhaled drug products should not be limited to concentration-dependent cytotoxicity tested in a monolayer as in the present work. Nonetheless, the $S A F E$ system may assist at early stages of formulation development by relating concentrations in formulations of FDA-approved drug products to concentrations used in human epithelial cell culture experiments. To further expand this approach, inflammatory effects such as the cytokine secretion of macrophages, transport studies to estimate bioavailability, the role of active transporters, and possible interactions with non-cellular barriers (e.g., mucus or surfactant) may be considered as additional endpoints for the safety assessments of orally inhaled drug products.

\section{References}

Adams, C. P. and Van Brantner, V. (2006). Market watch: Estimating the cost of new drug development: Is it really $\$ 802$ mil- lion? Health Aff 25, 420-428. doi:10.1377/hlthaff.25.2.420

Bakand, S., Winder, C., Khalil, C. et al. (2005). Toxicity assessment of industrial chemicals and airborne contaminants: Transition from in vivo to in vitro test methods: A review. Inhal Toxicol 17, 775-787. doi:10.1080/08958370500225240

Barakat, A., Krämer, J., de Souza Carvalho, C. et al. (2015). In vitro-in vivo correlation: Shades on some non-conventional dosage forms. Dissolut Technol 22, 19-22. doi:10.14227/ DT220215P19

Bracken, M. B. (2009). Why animal studies are often poor predictors of human reactions to exposure. JR Soc Med 102, 120 122. doi: $10.1258 / \mathrm{jrsm} .2008 .08 \mathrm{k} 033$

CDER, FDA (2017). Guidances for Industry: Waiver of In Vivo Bioavailability and Bioequivalence Studies for ImmediateRelease Solid Oral Dosage Forms Based on a Biopharmaceutics Classification System. https://www.fda.gov/downloads/ Drugs/Guidances/ucm070246.pdf

Chary, A., Hennen, J., Klein, S. G. et al. (2018). Respiratory sensitization: Toxicological point of view on the available assays. Arch Toxicol 92, 803-822. doi:10.1007/s00204-017-2088-5

Clippinger, A. J., Allen, D., Behrsing, H. et al. (2018a). Pathway-based predictive approaches for non-animal assessment of acute inhalation toxicity. Toxicol In Vitro 52, 131-145. doi:10.1016/j.tiv.2018.06.009

Clippinger, A. J., Allen, D., Jarabek, A. M. et al. (2018b). Alternative approaches for acute inhalation toxicity testing to address global regulatory and non-regulatory data requirements: An international workshop report. Toxicol In Vitro 48, 53-70. doi:10.1016/j.tiv.2017.12.011

DiMasi, J. A., Grabowski, H. G. and Hansen, R. W. (2016). Innovation in the pharmaceutical industry: New estimates of R\&D costs. J Health Econ 47, 20-33. doi:10.1016/j.jhealeco. 2016.01.012

Dipasri, K., Devarasetty, M., Yildiz, D. V. et al. (2016). Lungon-a-chip technologies for disease modeling and drug development. Biomed Eng Comput Biol 7, Suppl 1, 17-27. doi:10.4137/BECB.S34252

Donaldson, K., Borm P. J. A., Oberdorster, G. et al. (2008). Concordance between in vitro and in vivo dosimetry in the proinflammatory effects of low-toxicity, low-solubility particles: The key role of the proximal alveolar region. Inhal Toxicol 20, 53-62. doi:10.1080/08958370701758742

Drasler, B., Sayreb, P., Steinhäuser, K. G. et al. (2017). In vitro approaches to assess the hazard of nanomaterials. NanoImpact 8, 99-116. doi:10.1016/j.impact.2017.08.002

Eixarch, H., Haltner-Ukomadu, E., Beisswenger, C. et al. (2010). Drug delivery to the lung: Permeability and physicochemical characteristics of drugs as the basis for a pulmonary biopharmaceutical classification system (pBCS). J Epithel Biol Pharmacol 3, 1-14.

EMA (2016). Guideline on the Principles of Regulatory Acceptance of 3Rs (Replacement, Reduction, Refinement) Testing Approaches. EMA/CHMP/CVMP/JEG-3Rs/450091/2012. https://www.ema.europa.eu/en/documents/scientific-guideline/guideline-principles-regulatory-acceptance-3rs-replace ment-reduction-refinement-testing-approaches_en.pdf 
FDA (1997). Guidance for Industry: Drug Metabolism / Drug Interaction Studies in the Drug Development. http://www.wash ingtonlifescience.com/patient/drug_develop/pdfs/clin3.pdf

Fizeșan, I., Cambier, S., Moschini, E. et al. (2018). In vitro cellular models, a resourceful tool in respiratory toxicology. Farmacia 66, 573-580. doi:10.31925/farmacia.2018.4.2

Fogh, J., Fogh, J. M. and Orfeo, T. (1977). One hundred and twenty-seven cultured human tumor cell lines producing tumors in nude mice. J Natl Cancer Inst 59, 221-226. doi:10.1093/jnci/ 59.1.221

Fröhlich, E. (2017). Toxicity of orally inhaled drug formulations at the alveolar barrier: Parameters for initial biological screening. Drug Deliv 24, 891-905. doi:10.1080/10717544.2017.13 33172

Ghallab, A. and Bolt, H. M. (2014). In vitro systems: Current limitations and future perspectives. Arch Toxicol 88, 20852087. doi:10.1007/s00204-014-1404-6

Gonda, I. (2006). Systemic delivery of drugs to humans via inhalation. J Aerosol Med 19, 47-53. doi:10.1089/jam.2006.19.47

Halappanavar, S., Ede, J. D., Shatkin, J. A. et al. (2019). A systematic process for identifying key events for advancing the development of nanomaterial relevant adverse outcome pathways. NanoImpact 15, 100178. doi:10.1016/j.impact. 2019.100178

Harrison, R. K. (2016). Phase II and phase III failures: 20132015. Nat Rev Drug Discov 15, 817-818. doi:10.1038/ nrd.2016.184

Hastedt, J. E., Bäckman, P., Clark, A. R. et al. (2016). Erratum to: Scope and relevance of a pulmonary biopharmaceutical classification system AAPS/FDA/USP Workshop March 16-17th, 2015 in Baltimore, MD. AAPS Open 2, 4. doi:10.1186/s41120016-0005-2

Huh, D., Hamilton, G. A. and Ingber, D. E. (2011). From 3D cell culture to organs-on-chips. Trends Cell Biol 21, 745-754. doi:10.1016/j.tcb.2011.09.005

King, R. J. (1982). Pulmonary surfactant. J Appl Physiol Respir Environ Exerc Physiol 53, 1-8. doi:10.1152/jappl.1982.53.1.1

Klein, S. G., Serchi, T., Hoffmann, L. et al. (2013). An improved 3D tetraculture system mimicking the cellular organisation at the alveolar barrier to study the potential toxic effects of particles on the lung. Part Fibre Toxicol 10, 31. doi:10.1186/17438977-10-31

Kong, B., Seog, J. H., Graham, L. M. et al. (2011). Experimental considerations on the cytotoxicity of nanoparticles. Nanomedicine 6, 929-941. doi:10.2217/nnm.11.77

Li, A. P. (2004). Accurate prediction of human drug toxicity: A major challenge in drug development. Chem Biol Interact 150, 3-7. doi:10.1016/j.cbi.2004.09.008

Lieber, M., Smith, B., Szakal, A. et al. (1976). A continuous tumor-cell line from a human lung carcinoma with properties of type II alveolar epithelial cells. Int J Cancer 17, 62-70. doi:10.1002/ijc.2910170110

Mahmoudi, M., Hofmann, H., Rothen-Rutishauser, B. et al. (2012). Assessing the in vitro and in vivo toxicity of superparamagnetic iron oxide nanoparticles. Chem Rev 112, 23232338. doi:10.1021/cr2002596
Moore, T., Rodriguez-Lorenzo, L., Hirsch, V. et al. (2015). Nanoparticle colloidal stability in cell culture media and impact on cellular interactions. Chem Soc Rev 44, 6287-6305. doi:10.1039/C4CS00487F

Oberdörster, G. (2010). Safety assessment for nanotechnology and nanomedicine: Concepts of nanotoxicology. J Intern Med 267, 89-105. doi:10.1111/j.1365-2796.2009.02187.x

OECD (2000). Guidance Document on the Recognition, Assessment and Use of Clinical Signs as Humane Endpoints for Experimental Animals Used in Safety Evaluation. OECD Series on Testing and Assessment No. 19. OECD Publishing, Paris. doi:10.1787/9789264078376-en.

OECD (2009). Test No. 436: Acute Inhalation Toxicity Acute Toxic Class Method. OECD Guidelines for the Testing of Chemicals, Section 4. OECD Publishing, Paris. doi:10.1787/9789264076037-en

OECD (2018a). Test No. 442E: In Vitro Skin Sensitisation Assays Addressing the Key Event on Activation of Dendritic Cells on the Adverse Outcome Pathway for Skin Sensitisation. OECD Guidelines for the Testing of Chemicals, Section 4. OECD Publishing, Paris. doi:10.1787/9789264264359-en

OECD (2018b). Guidance Document on Good In Vitro Method Practices (GIVIMP). OECD Series on Testing and Assessment No. 286. OECD Publishing, Paris. doi:10.1787/ 9789264304796-en

Paur, H. R., Cassee, F. R., Teeguarden, J. et al. (2011). In-vitro cell exposure studies for the assessment of nanoparticle toxicity in the lung - A dialog between aerosol science and biology. J Aerosol Sci 42, 668-692. doi:10.1016/j.jaerosci.2011.06.005

Pritchard, J. F., Jurima-Romet, M., Reimer, M. L. J. et al. (2003). Making better drugs: Decision gates in non-clinical drug development. Nat Rev Drug Discov 2, 542-553. doi:10.1038/ $\operatorname{nrd} 1131$

Rowe, C. R., Sheskey, P. J. and Quinn, E. M. (eds.) (2009). Handbook of Pharmaceutical Excipients. $6^{\text {th }}$ edition. London, UK: Pharmaceutical Press. http://pharmama.info/wp-content/ uploads/2018/10/Excipients.pdf

Rushton, E. K., Jiang, J., Leonard, S. S. et al. (2010). Concept of assessing nanoparticle hazards considering nanoparticle dosemetric and chemical/biological response-metrics. J Toxicol Environ Health A 73, 445-461. doi:10.1080/15287390903489422

Sauer, U. G., Vogel, S., Hess, A. et al. (2013). In vivo-in vitro comparison of acute respiratory tract toxicity using human 3D airway epithelial models and human A549 and murine 3 T3 monolayer cell systems. Toxicol In Vitro 27, 174-190. doi:10.1016/j.tiv.2012.10.007

Scherließ, R. (2011). The MTT assay as tool to evaluate and compare excipient toxicity in vitro on respiratory epithelial cells. Int J Pharm 411, 98-105. doi:10.1016/j.ijpharm.2011.03.053

Schleh, C., Kreyling, W. G. and Lehr, C. M. (2013). Pulmonary surfactant is indispensable in order to simulate the in vivo situation. Part Fibre Toxicol 10, 6. doi:10.1186/1743-8977-10-6

Schmid, O. and Stoeger, T. (2016). Surface area is the biologically most effective dose metric for acute nanoparticle toxicity in the lung. J Aerosol Sci 99, 133-143. doi:10.1016/j.jaerosci. 2015.12.006 
Schmid, O. and Cassee, F. R. (2017). On the pivotal role of dose for particle toxicology and risk assessment: Exposure is a poor surrogate for delivered dose. Part Fibre Toxicol 14, 52. doi:10.1186/s12989-017-0233-1

Shen, J. and Burgess, D. J. (2016). In vitro-in vivo correlation for complex non-oral drug products: Where do we stand? J Contol Release 219, 644-651. doi:10.1016/j.jconrel.2015.09.052

Silva, E. D. and Sørli, J. B. (2018). Animal testing for acute inhalation toxicity : A thing of the past ? Appl In Vitro Toxicol 4, 89-90. doi:10.1089/aivt.2017.0037

Sivars, K. B., Sivars, U., Hornberg, E. et al. (2018). A 3D human airway model enables prediction of respiratory toxicity of inhaled drugs in vitro. Toxicol Sci 162, 301-308. doi:10.1093/ toxsci/kfx255

Strickland, J., Clippinger, A. J., Allen, D. et al. (2018). Status of acute systemic toxicity testing requirements and data uses by U.S. regulatory agencies. Regul Toxicol Pharmacol 94, 183196, doi:10.1016/j.yrtph.2018.01.022

Sørli, J. B., Da Silva, E., Bäckman, P. et al. (2016). A proposed in vitro method to assess effects of inhaled particles on lung surfactant function. Am J Respir Cell Mol Biol 54, 306-311. doi:10.1165/rcmb.2015-0294MA

United Nations (2017). GHS Classification. Part 3: Health Hazards. 115-116. http://www.unece.org/fileadmin/DAM/
trans/danger/publi/ghs/ghs_rev02/English/03e_part3.pdf

Upadhyay, S. and Palmberg, L. (2018). Air-liquid interface: Relevant in vitro models for investigating air pollutant-induced pulmonary toxicity. Toxicol Sci 164, 21-30. doi:10.1093/toxsci/ kfy053

Wiemann, M., Sauer, G. U., Vennemann, A. et al. (2018). In vitro and in vivo short-term pulmonary toxicity of differently sized colloidal amorphous $\mathrm{SiO}_{2}$. Nanomaterials 8, 160. doi:10.3390/ nano8030160

Woodcock, J. and Woosley, R. (2008). The FDA critical path initiative and its influence on new drug development. Annu Rev Med 59, 1-12. doi:10.1146/annurev.med.59.090506.155819

\section{Conflict of interest}

The authors declare no conflict of interest.

\section{Acknowledgements}

Julia Metz and Marius Hittinger were financially supported by the BMBF project AeroSafe (031L0128C). Katharina Knoth, Marius Hittinger, Markus Limberger, Horst Zimmer and Henrik Groß were involved in the ZIM project NanOK. We thank Jak Masters for his help in proofreading the manuscript. 